\title{
Area effects of bednet use in a malaria-endemic area in Papua New Guinea
}

\author{
J. L. K. Hii ${ }^{1,2^{\star}}$, T. Smith ${ }^{1,3}$, P. Vounatsou ${ }^{3}$, N. Alexander ${ }^{1}$, A. Mai ${ }^{1}$, E. Ibam' and M. P. Alpers' ${ }^{1}{ }^{1}$ Papua New \\ Guinea Institute of Medical Researd, P.O. Box 378, Madang, Papua New Guinea; ${ }^{2}$ School of Public Health and Tropical \\ Medicine, Fames Cook University, Townsville, Queensland 4811, Australia; ${ }^{3}$ Swiss Tropical Institute, Socinstrasse 57, Postfach \\ CH-4002, Basel, Switzerland
}

\begin{abstract}
Relationships between area coverage with insecticide-free bednets and prevalence of Plasmodium falciparum were investigated in 7 community-based surveys over a 33-month period in 1990-93 in 6 villages in the Wosera area of Papua New Guinea. Spatial patterns in circumsporozoite rates for $P$. falciparum, $P$. vivax isomorphs $\mathrm{K} 210$ and $\mathrm{K} 247$, and $P$. malariae, and the proportions of mosquito blood meals positive for specific human, goat, cat, dog and pig antigens were determined using ELISAs. $P$. falcipanum prevalence in humans was better explained by bednet coverage in the immediate vicinity than by personal protection alone. Circumsporozoite rates for both $P$. falciparum and $P$. vivax were also inversely related to coverage with bednets. There was some increase in zoophagy in areas with high coverage, but relatively little effect on the human blood index or on overall mosquito densities. In this setting, protracted use of untreated bednets apparently reduces sporozoite rates, and the associated effects on prevalence are greater than can be accounted for by personal protection. Even at high bednet coverage most anophelines feed on human hosts, so the decreased sporozoite rates are likely to be largely due to reduction of mosquito survival. This finding highlights the importance of local vector ecology for outcomes of bednet programmes and suggests that area effects of untreated bednets should be reassessed in other settings.
\end{abstract}

Keywords: malaria, Plasmodium falciparum, Plasmodium vivax, prevalence, bednets, Anopheles punctulatus, sporozoite rate, human blood inclex, Papua New Guinea

\section{Introduction}

Village-scale trials have found that insecticide-treated bednets (ITNs) can substantially reduce the survival of malaria vectors, as assessed by parous and sporozoite rates. They have also found measurable decreases in the density of mosquitocs (MAGESA et al., 1991 ; ROBERT \& CARNEVALE, 1991; BEACH et al.,1993; KARCH et al., 1993) and hence of the rate of inoculation of unprotected individuals. It follows that ITNs can protect not only the individuals sleeping under them, but also those living nearby. Indeed, BINKA et al. (1998) found that mortality rates in children without nets were lower if they lived close to concentrations of ITN users.

Mass effects of bednets have been thought to require insecticide treatment of the nets, consistent use over a wide area, and an anthropophilic vector (LINES, 1996). While observational studies [e.g., CAMPBELI et al. (1987) in The Gambia and GENTON et al. (1994) in Papua New Guinea] suggest that untreated nets (UTNs) also protect against Plasmodium falciparum infection, the only published randomized controlled trial of UTNs found no significant protection (SNOw et al., 1988a). There were also no significant differences in sporozoite antibody levels between children sleeping under UTNs and those who did not, although those under nets suffered significantly fewer mosquito bites (SNOW et al., 1989).

It has consequently been proposed that the apparent beneficial effects of UTNs in some studies might merely reflect diversion of frustrated host-seeking mosquitoes on to unprotected individuals sleeping nearby (SNOW er $a l, 1988 \mathrm{a}, 1988 \mathrm{~b} ; 1998$ ). Differences in infection rates between UTN users and unprotected individuals would then reflect redistribution of bites rather than net decreases in inoculations, and thus widespread use of UTNs would have little overall public health impact, possibly even disadvantaging those who could not obtain them.

In keeping with this hypothesis, in the Papua New Guinea study, GENTON et al. (1994) found that some of the apparent protection might indeed be gained by diverting mosquitoes to non-users of bednets in the same house. While patterns of antimalarial use could account for some variation in prevalence (GENTON et al., 1995) they could not explain the bednet effects (SMITH et al.,

\footnotetext{
*Author for correspondence; e-mail jeffrey_hii(a)ausaid.gov.au
}

2001). The very large apparent efficacy motivated us to look more closely into the effects of these bednets, making use of a geographical information system to determine whether UTNs also affect inhabitants of neighbouring houses.

First, we cxamined whether the prevalence of $P$. falciparum parasitaemia was affected by the bednet coverage in nearby houses, and assessed the scale of the effects that we found. Changes in vector bionomics must mediate such area effects. We therefore examined whether coverage affects the human blood index (HBI), which measures the degree of anthropophagy. We also assessed rates of zoophagy and examined whether the UTNs affect vector survival, using the sporozoite rate as an indirect measure of this important determinant of malaria-transmission intensity. These analyses enable us to propose a mechanism for the apparent effects of UTNs on parasite prevalence.

\section{Materials and Methods}

Study area and malaria prevalence data

The study was carried out in the Wosera area of the East Sepik Province of Papua New Guinea as part of the Malaria Vaccine Epidemiology and Evaluation Project (ALPERs et al., 1992). HIl et al. (1997) described the spatial and temporal patterns in densities of the malaria vectors in this area. The main vectors are Anopheles punctulatus s.s., $A n$. koliensis, $A n$. farauti s.l., and $A n$. karwari. Less frequent anophelines are $A n$. bancroftit and An. longirostris. Malariological surveys in 1990-92 found a high endemicity of $P$. falciparum, $P$. vivax and $P$. malariae (GENTON et al, 1995). The present analyses used parasitological records from these surveys for individuals aged $<20$ years whose houses could be geocoded ( 3459 records).

\section{Bednet coverage}

Individual households in the area have used UTNs for decades for reasons including privacy, reduction of insect nuisance and dust avoidance. During the sample surveys of GENTON et al. (1995) each individual was asked whether he/she had slept under a bednet the previous night. Bednet coverage was then defined for each of a series of radii around each individual's house $(25,50$, $100 \mathrm{~m})$. Thus, coverage within $100 \mathrm{~m}\left(\mathrm{C}_{100}\right)$ was defined as the proportion of all responses within $100 \mathrm{~m}$ that indicated bednet use; $\mathrm{C}_{25}$ was the proportion within 
$25 \mathrm{~m} ; \mathrm{C}_{0}$ was the coverage within the same house as the index individual.

\section{Sampling of anophelines}

Mosquito densities were determined by monthly mosquito collections among 5-6 sectors of each village (total of 10 villages) from January 1991 to September 1993. Within each sector, a random inhabitant was selected each month, and his or her home defined as the index house. Two men, one inside and the other outside this house carried out landing collections of hostseeking mosquitoes from sunset to midnight. A pair of new collectors resumed collections after midnight until sunrise. To maintain privacy, indoor catches were made some distance from sleeping occupants of the house. Collections were not made under bednets even when these were in use. For further details see HII et al. (1997).

Indoor resting collections were made at dawn inside the bedrooms of the index house and in 3 neighbouring houses (HII et al, 1997). Mosquitoes resting on walls and on outside, but not inside surfaces of UTNs were collected. Mosquitoes resting outdoors were collected between 06:30 and 07:30 from the area immediately around the index house and 4 adjacent houses.

\section{Analysis of blood meals}

Midguts of fully engorged Anopheles mosquitoes from resting collections were tested by EI.ISA for each of human, pig, dog, cat and goat blood. Details of sampling and ELISA techniques are given by HII et al. (1997). For each house where resting collections were carried out, both the proportions of blood meals containing human blood (the $\mathrm{HBI}$ ), and the overall proportion of blood meals containing identified non-human blood were calculated.

\section{Circumsporozoite rate estimation}

Circumsporozoite antigens for $2 P$. vivax phenotypes (PVK210 and PVK247) (W1RTZ et al., 1991, 1992), $P$. falciparim (WIRTZ et al, 1987) and $P$. malariae (COLLINS et al., 1988) were detected in mosquito pools containing head-thoraces or whole bodies by specific ELISAs. In brief, 96-well microtitre plates (Dynatech Laboratories, Inc., Virginia, VA, USA) were incubated at room temperature overnight with monoclonal antibody (MAb) NSV3 $(0.025 \mu \mathrm{g} / 50 \mu \mathrm{L}$ of phosphate-buffered saline [PBS] for PVK210, MAb PV21247-499 $(0.1 \mu \mathrm{g} / 50 \mu \mathrm{L}$ of PBS) for PVK247, MAb PF2A10 $(0.1 \mu \mathrm{g} / 50 \mu \mathrm{L}$ of PBS) for $P$. falciparum, and $\mathrm{MAb}$ PB32 $(0.25 \mu \mathrm{g} / 50 \mu \mathrm{L}$ of PBS $)$ for $P$. malariae, then incubated with blocking buffer for $1 \mathrm{~h}$ at room temperature. One positive and 8 negative controls were run on each plate, and the absorbances were read at $405 \mathrm{~nm}$ on a Multiskan ELISA reader. Positive samples were defined as where the optical density was greater than the mean +3 standard deviations of a set of 8 negative controls. These samples were re-assayed to confirm them as positive. Control equivalencies were determined to be $100 \mathrm{pg}$ of R32tet $32=400$ sporozoites for $P$. falciparum, $40 \mathrm{pg}$ of NS1V2 $=400$ sporozoites for VK210,5 $\mathrm{ng}$ of VK247-9 = 500 sporozoites for VK247 and $0.25 \mu \mathrm{g}$ of $\mathrm{PC}=500$ sporozoites for $P$. malariae.

Maps of smoothed spatial patterns in the circumsporozoite rates were produced using conditional autoregressive statistical models (BERNARDINELLI \& MONTOMOLI, 1992) with distance priors (VOUNATSOU et $a l, 2000$ ) and logistic link functions. These models were fitted using the package BUGS (Bayesian Updating using Gibbs Sampling) (Thomas et al., 1992). Additional terms in bednet coverage, measured by $\mathrm{C}_{25}$, were added to these models for estimation of coverage effects on circumsporozoite rates, which allowed control of possible spatially structured confounding.

\section{Results}

Parasite prevalence and bednet coverage

The detailed patterns of parasite prevalence by age are described elsewhere (GENTON et al., 1995) and the effects of bednet coverage on these patterns are described by SMITH et al. (2001). Of the 3459 microscope slides included in the present analyses, $1640(47 \%)$ were positive for asexual stages of $P$. falciparum.

To the question 'Did you sleep in a mosquito net last night?', 2354 individuals from geocoded houses provided 6223 responses of which $2551(41 \cdot 0 \%)$ were positive. Bednet coverage was highest in the centre and lowest in the western part of the study area (Fig. 1).

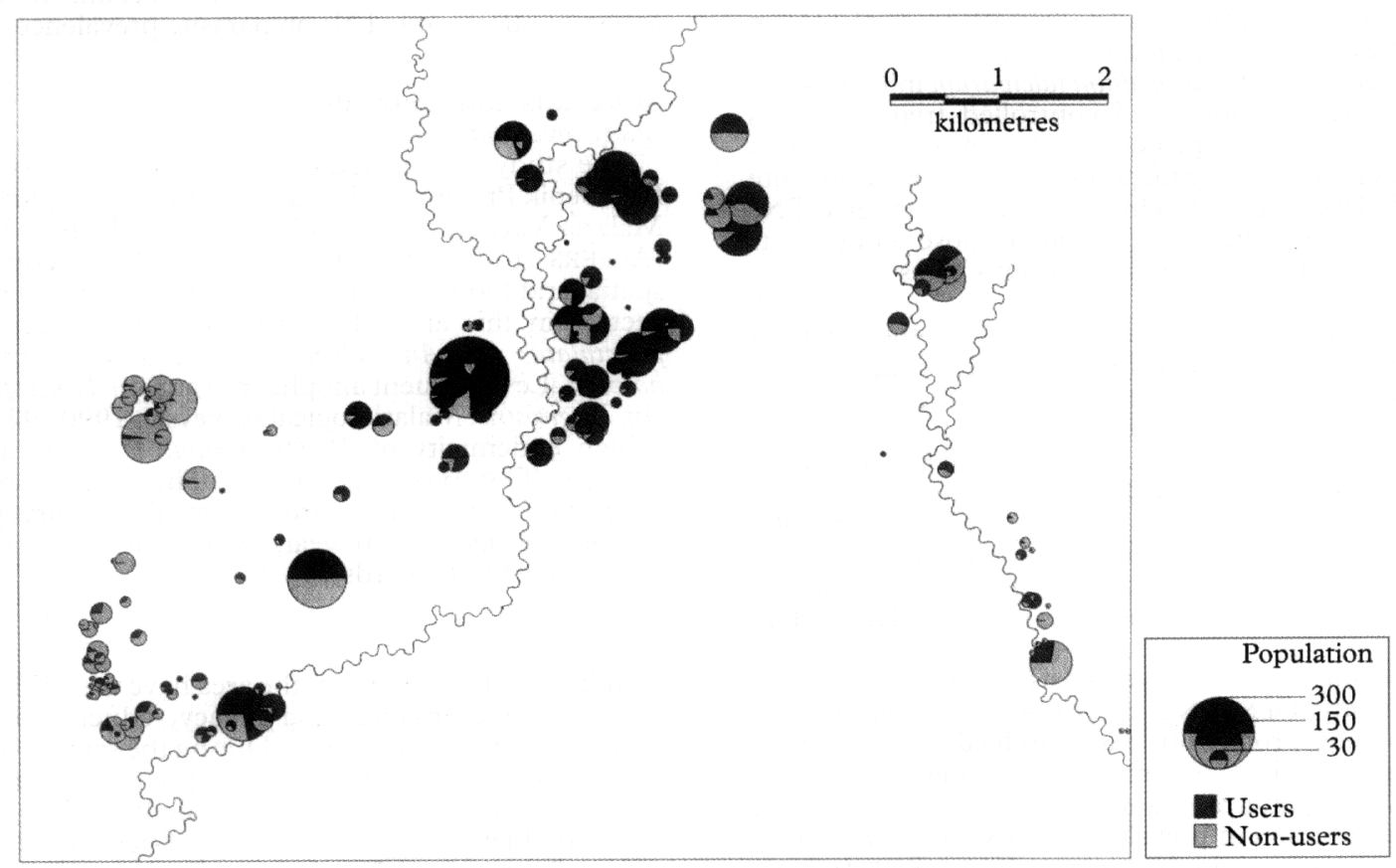

Fig. 1. Untreated bednet (UTN) coverage by cluster of houses (Wosera, Papua New Guinea). Pie area is proportional to the population recorded in the demographic surveillance on 31 December 1991 . The shading indicates the UTN coverage ( $D$ indicates UTN use; indicates unprotected individuais). 
In age-adjusted logistic models, the odds for $P$. falciparum infection associated with the individual responses to the question on bednet use the previous night $(D)$ was $0.52(95 \%$ confidence interval $[\mathrm{CI}] 0.46,0.60)$. However, irrespective of the radius $(r)$ used, the bednet coverage, $\mathrm{C}_{r}$, accounted for more variation in $P$. falcipar$u m$ prevalence than did these individual responses. In logistic models including terms for coverage within the same house $\left(\mathrm{C}_{0}\right)$, within $25 \mathrm{~m}\left(\mathrm{C}_{25}\right)$, or $50 \mathrm{~m}\left(\mathrm{C}_{50}\right)$, the additional effect of individual bednet use was small (Fig. 2). However, $C_{0}$ itself had a somewhat smaller effect on prevalence than did either $\mathrm{C}_{25}$ or $\mathrm{C}_{50}$ (Fig. 2). Correspondingly, the likelihood ratio (LR) statistic testing the effect of $\mathrm{C}_{0}$ (adjusting for individual responses) was 27.0 , compared with 36.4 for $C_{25}, 41.3$ for $C_{50}$ and 37.8 for $\mathrm{C}_{100}$ (all $P<0.0001$ ). The corresponding LR statistics testing the effect of individual responses to the question on bednet use were 24.6 (adjusting for $\mathrm{C}_{0}$ ), 31.7 (adjusting for $\mathrm{C}_{25}$ ), 34.9 (adjusting for $\mathrm{C}_{50}$ ) and 37.9 (adjusting for $\mathrm{C}_{100}$ ). Since the magnitudes of the coverage effects were little affected by the radius used (Fig. 2), further analyses used the smallest radius $(25 \mathrm{~m})$ that gave reasonably precise estimates of coverage. This radius corresponded approximately to the radius of a small hamlet.

\section{Mosquito densities}

Comparison of Figure 1 with maps of biting rates given by HII et al. (1997) indicates that vector densities for $A n$. punctulatus, An. koliensis, and An. karwari are positively correlated with bednet coverage. Those for $A n$, farauti

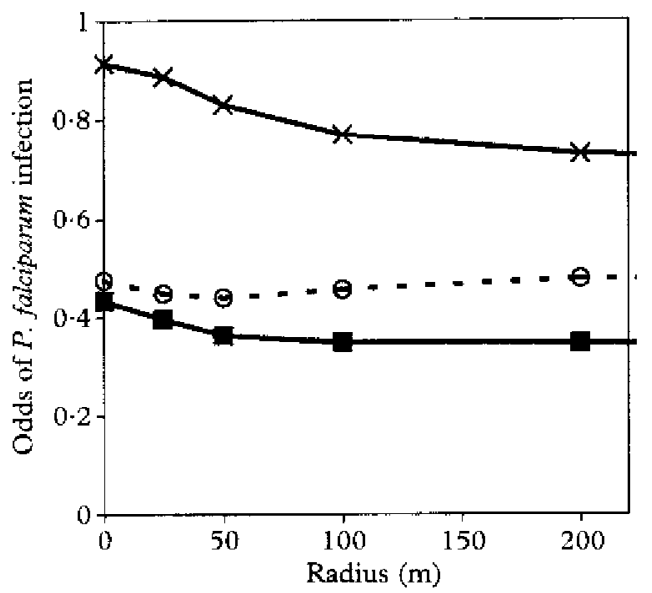

Fig. 2. P. falciparum positivity by untreated bednet (UTN) use and coverage (Wosera, Papua New Guinea). Estimated odds of being infected relative to an individual in an area with no UTN use. Crosses, effect of bednet use, adjusted for coverage; squares, effect of coverage (unadjusted); circles, effect of coverage adjusted for bednet use. Distinct logistic models were fitted for each radius analysed. s.l., An. bancroftii and An. longirostris densities are negatively associated with $\mathrm{C}_{25}$.

Blood meal analysis

The HBI in resting An. punctulatus and An. koliensis was 0.90 and 0.79 , respectively (HII et al., 1997). In $A n$. punctulatus, HBI tended to decline with increasing $\mathrm{C}_{25}$ (logistic regression: $\operatorname{LR} \chi^{2}=5.90 ; l=0.015$ ) although, even in areas where bednet usage was universal, $78 \%$ of resting female $A n$. punctulatus had fed on humans. The corresponding decline was not evident in $A n$. koliensis (LR $\chi^{2}=1.0 ; P=0.3$ ). In total, $19 \cdot 2 \% A n$. punctulatus and $10.5 \%$ An. koliensis blood meals tested positive for non-human blood (pig, cat, dog, or goat) with dog the most frequent non-human host, and the proportion of blood meals with non-human blood increased with $\mathrm{C}_{25}$ in both species (An. punctulatus: IR $\chi^{2}=11.2 ; P=$ $0.0008 ;$ An. koltensis: LR $\chi^{2}=11.3 ; P=0.0008$ ). There were insufficient data to test whether rates of either anthropophagy or zoophagy varied with $\mathrm{C}_{25}$ in the minor vectors $A n$. karwari, $A n$. farauti s.l., $A n$. bancroftii and An. longirostris.

\section{Circumporozoite rates}

From a total of 5484 all-night landing catches, 114973 mosquitoes were tested for circumsporozoite antigens: 754 specimens were positive for circumsporozoite antigen of $P$. falcipamim, 361 for $P$. vivax (PVK210 and PVK247 combined), and 99 for $P$. malariae (Table 1). An. koliensis and An. punctulatus had the highest circumsporozoite rates of the 6 species (Table 1) as well as the highest biting densities (HII et al., 1997).

Analyses that did not include spatial autocorrelation indicated marked trends for circumsporozoite rates to decrease as $\mathrm{C}_{25}$ increased. In $A n$. punctulatus, this decline was significant and of comparable magnitude for both $P$. falciparum (logistic regression $L R x^{2}=20.2 ; P<0.0001$; odds ratio $=0.41$; Table 2 , Fig. 3a) and $P$. vivax $\left(\mathrm{LR} \chi^{2}=5.2 ; P=0.023\right.$; Fig. 3b). In An. koliensis the declines associated with $100 \%$ bednet coverage were of similar magnitude to those in $A n$. punctulatus ( $P$. falciparum: $L R \chi^{2}=22.9 ; \quad P<0.0001$; Fig. 3a; $P$. vivax: $\mathrm{LR} \chi^{2}=2.8 ; P=0.10$; Fig. 3b). Data for minor vectors and for $P$. malariae were too sparse for such analyses.

$P$. falciparum circumsporozoite rates were highest in the western and north-eastern parts of the study area, for both $A n$. punctulatus (Fig. 4a) and An. koliensis (Fig. 4b). This pattern complemented that of bednet coverage. $P$. vivax sporozoites were also more often found in the western part of the study area (Fig. 4c, 4d), but remained low in the north-eastern part (Nale-1 village).

Estimates, allowing for spatial structure, of the effects of $\mathrm{C}_{2,}$ on circumsporozoite rates had broader confidence intervals than unadjusted estimates (Table 2). However, although some of these intervals overlapped with unity, the estimated coverage effects were of similar magnitude for both Plasmodium species, and also for both major

Table 1. Overall circumsporozoite rates (\%) by Plasmodium and mosquito species (Wosera, Papua New Guinea, 1991-93)

\begin{tabular}{|c|c|c|c|c|}
\hline Vector & $\begin{array}{c}\text { Total } \\
\text { mosquitoes } \\
\text { evaluated }\end{array}$ & P. falciparum & P. vivax & P. malariae \\
\hline An. punctulatts & 42584 & $0.76(0.68,0.84)$ & $0.34(0.29,0.40)$ & $0.09 \quad(0.07,0.12)$ \\
\hline An. koliensis & 49000 & $0 \cdot 77(0 \cdot 69,0 \cdot 85)$ & $0.19(0.17,0.22)$ & $0.09 \quad(0.07,0.13)$ \\
\hline An. karwari & 15007 & $0.32(0.24,0.42)$ & $0.07(0.05,0.11)$ & $0.04 \quad(0.02,0.09)$ \\
\hline An. farauti s.l & 4438 & $0.14(0.06,0.30)$ & $0.03(0.01,0.10)$ & $0.14(0.06,0.31)$ \\
\hline An. longirostris & 3089 & $0.10^{2}(0.03,0.30)$ & $0.03^{2}(0.01,0.13)$ & $0.07^{\circ}(0.02,0.26)$ \\
\hline An. bancroftii & 855 & $0.23^{\mathrm{a}}(0.06,0.93)$ & $0.12^{\mathrm{a}}(0.03,0.47)$ & $0.12^{\mathrm{a}}(0.02,0.83)$ \\
\hline
\end{tabular}

Circumsporozoite rate was calculated by ELISA-positive mosquitoes captured on human bait. Figures in parentheser are exact binomial $95 \%$ confidence intervals.

"Sporozoite-positives found in whole bodies only. 
Table 2. Effects of untreated bednet coverage on sporozoite rate, adjusted for spatial pattern (Wosera, Papua New Guinea)

\begin{tabular}{|c|c|c|c|c|c|}
\hline \multirow[b]{2}{*}{ Vector } & \multirow[b]{2}{*}{ Parasite } & \multicolumn{2}{|c|}{ No allowance for spatial pattern } & \multicolumn{2}{|c|}{ Analysis allowing for spatial pattern } \\
\hline & & $\begin{array}{l}\text { Odds of CSP } \\
\text { positivity }\end{array}$ & $(95 \% \mathrm{CI})$ & $\begin{array}{c}\text { Odds of CSP } \\
\text { positivity }^{\mathrm{a}}\end{array}$ & $(95 \% \mathrm{CI})$ \\
\hline $\begin{array}{l}\text { An. punctulatts } \\
\text { An. koliensis } \\
\text { An. punctulatus } \\
\text { An. koliensis }\end{array}$ & $\begin{array}{l}P . \text { falciparum } \\
P . \text { falciparum } \\
P . \text { vivax } \\
P . \text { vivax }\end{array}$ & $\begin{array}{l}0.41 \\
0.41 \\
0.46 \\
0.55\end{array}$ & $\begin{array}{l}(0.28,0.59) \\
(0.28,0.58) \\
(0.24,0.88) \\
(0.28,1.12)\end{array}$ & $\begin{array}{l}0.30 \\
0.62 \\
0.35 \\
0.58\end{array}$ & $\begin{array}{l}(0.17,0.49) \\
(0.37,1.00) \\
(0.16,0.81) \\
(0.25,1.31)\end{array}$ \\
\hline
\end{tabular}

Estimated odds for a sampled house with $\mathrm{C}_{25}=100 \%$ compared with a house with $\mathrm{C}_{25}=0 \%$.

CSP, circumsporozoite protein; $C_{25}$, coverage of households with bednets within a $25-\mathrm{m}$ radius.
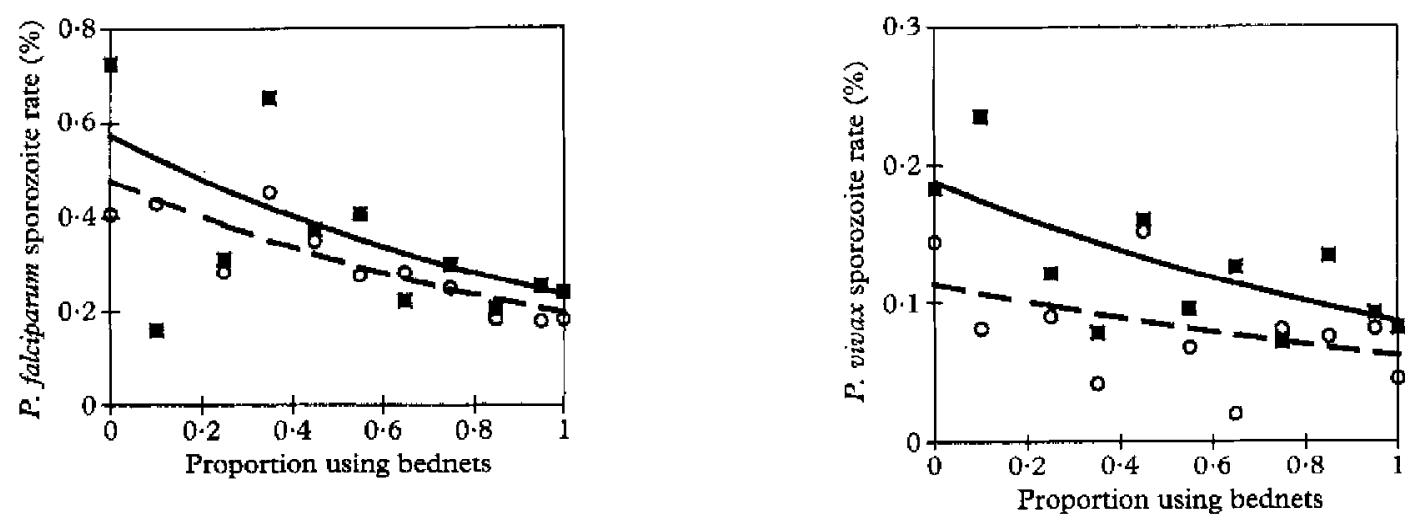

Fig. 3. Circumsporozoite rate by untreated bednet coverage (Wosera, Papua New Guinea). Squares, An. punctulatus (observed); circles, $A n$. koliensis (observed); solid lines, $A n$. punctulatus (fitted); broken lines, $A n$. koliensis (fitted).

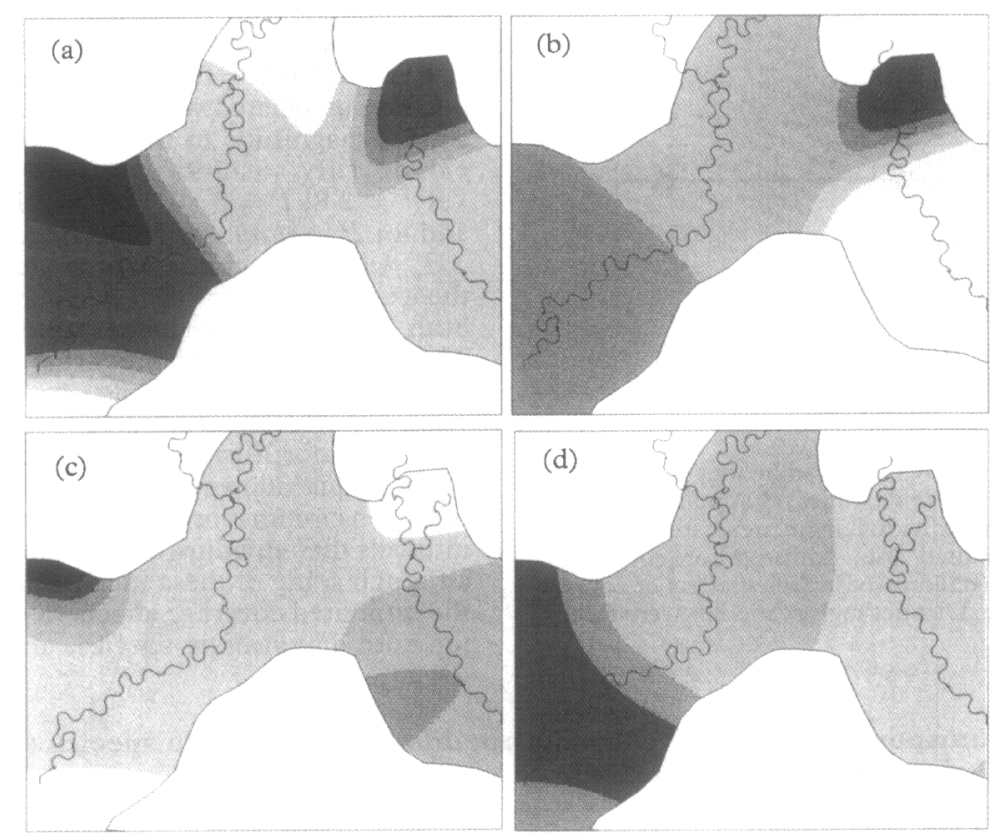

Fig. 4. Spatially smoothed circumsporozoite rates in the Wosera area (Papua New Guinea) during 1991-93. (a). P. falcipanum circumsporozoites in An, punctulatus. $=1.0 \% ; 0,0.8-1.0 \% ; 0,0.7-0.8 \% ; 0,0.6-0.7 \% ; 0,0.5-0.6 \%, \square,<0.5 \%$. (b). $P$ falciparum circumsporozoites in An. koliensis (shading as for Fig. 4a). (c). P. vivax circumsporozoites in An. punctulatus. $\square,>0.5 \%$; $0.4-0.5 \% ; 0,0-3-0.4 \% ; \square, 0.2-0.3 \% ; \square, 0.1-0.2 \% ; \square,<0.1 \%$. (d) $P$. vivax circumsporozoites in An. koltensis (shading as for Fig. 4c).

vectors, indicating a consistent effect of bednet coverage on the circumsporozoite rate.

\section{Discussion}

The demonstration that ITNs are an effective intervention against malaria mortality has encouraged their widespread introduction in malaria-endemic areas. However, there are major operational difficulties in ensuring that ITNs receive their periodic re-treatment (ZIMICKI, 1996). Many remote communities will undoubtedly be left with high coverage of effectively untreated nets. 
The only published randomized controlled trial of UTNs (SNOW et al., 1988a) found no significant protection. Yet the efficacy of ITNs in community randomized trials with UTNs as control was lower than that where control groups had no nets, suggesting that UTNs have a positive, although small, efficacy (LENGELER, 1998). The UTN effects found in Wosera (GENTON et al, 1994) were surprisingly large, and demand an explanation. Confounding can never be ruled out in observational studies, but neither the type of house construction, nor repellent effects of wood fires (GENTON et al., 1994), nor variations in antimalarial treatment of the hosts (GENTON et al., 1995; SMITH et al., 2001) account for the bednel effects. The present analyses attempt to explain the bednet effects by analysing entomological processes that might be involved, rather than by seeking further possible confounders.

We first considered whether the associations between malaria prevalence and UTN use arose because of protection of individual hosts, or via effects of the nets on the mosquito population. Individual responses will give an exaggerated idea of variation in use within households if UTN usage varies from night to night. In such circumstances $\mathrm{C}_{0}$ could be a better measure of individual level protection over time than the questionnaire response assigned to an individual. Indeed in the nearby Madang province, BURKoT et al. (1989) found that the number of bednets in a house provides a better predictor of long-term bednet use than interview data. In principle, apparent coverage effects might therefore simply reflect individual protection together with imperfect measurement of bednet usage.

In Wosera, spot chccks of actual bednet usage confirmed that data for self-reported use the previous night were reasonably accurate (GENTON et al., 1994) and should thus give reasunably unbiased estimates of coverage. At the same time, the finding of GENTON et al. (1994), that non-net-users in the same houses tended to be more often infected than people in houses where no one sleeps under a net, suggests that patterns of UTN use within households do not change continuously. If different people used the UINs on different nights this would reduce within-house variation in prevalence. These observations suggest that our modelling procedures correctly distinguish area and individual effects, and hence that the better fit of logistic models with terms in $\mathrm{C}_{25}$ and $\mathrm{C}_{50}$ than corresponding models in $\mathrm{C}_{0}$ is evidence for genuine area effects. The relatively small residual effect of self-reported UTN use in models allowing for coverage indicates that the major impact of UTNs in Wosera is a result of area effects rather than individual protection.

Following LINES et al. (1987) and SNOW et al. (1988a, 1988b), GENTON et al. (1994) contended that diversion of mosquitoes on to unprotected individuals explained why non-users in the same house as users can be at high risk. There is no contradiction between this finding and that of overall protective effects of net coverage: most of the victims of diversion are in areas of low net-coverage, while the protective effects of UTN coverage appear to be more important at high $\mathrm{C}_{25}$. The effects of $\mathrm{C}_{25}$ on the HBI and on rates of animal feeding confirm that the UTNs divert mosquitoes on to alternative hosts. Zooprophy. lactic effects have also been observed in the Madang area of Papua New Guinea (CHARLWOOD et al., 1986). However, the less anthropophilic vector $A n$. farauti is more important in the Madang area, and the people there keep many more pigs, so there is more potential for effective zooprophylaxis in Madang than in Wosera.

We do not believe that diversion can be the main reason for the area effects in Wosera. First, the effect of UTN use on HBI was rather small, and even when net coverage was high, reaching $82 \%$ in one village [see GENTON et al. (1994)], most of the fed mosquitoes belonging to the 2 major vector species had still managed to find a human host. Secondly, the protection against parasitaemia associated with high coverage, even in models that adjusted for individual-level UTN use, argues that diversion is a secondary phenomenon. If diversion were important, we would expect a large individual protection effect but a negative effect of coverage. It appears that the effects of diversion on to unprotected human hosts are more than compensated for by the effects on the circumsporozoite rate.

In contrast to the effect on the HBI, the associations of $\mathrm{C}_{25}$ with the circumsporozoite rates for $P$. falcipanim are substantial. This raises a 'chicken and egg' problem. Does the effect of coverage on circumsporozoite rate merely reflect lower parasite prevalence among individuals in areas with high net coverage, or vice versa? Although overall there is less variation with $\mathrm{C}_{25}$ in prevalence than in circumsporozoite rate [since there is little effect of $\mathrm{C}_{25}$ on the prevalence in adults (SMITH et $a l ., 2001)]$, children contribute disproportionately to the reservoir of individuals infective to mosquitoes (MUIRHEAD-THOMSON, 1954; GRAVES et al., 1988). Consequently, by considering only data for $P$. falciparum we cannot dismiss the possibility that vatiations in prevalence in humans account for the variations in circumsporozoite rates.

$P$. vivax provides a route out of this logical conundrum. The relationships of the circumsporozoite rates with $\mathrm{C}_{25}$ are similar in $P$. vivax and $P$. falcipamm (Fig. 3), so the same processes are probably involved in determining this relationship for both parasites. However, there is little relationship between $\mathrm{C}_{25}$ and $P$. vivax prevalence in humans (SMITH et al, 2001), so the trend with $\mathrm{C}_{25}$ in circumsporozoite rates for $P$. vivax is not a result of a trend with $\mathrm{C}_{25}$ in parasitacmia. Variation in prevalence in humans is therefore unlikely to be the main cause of the spatial pattern in the circumsporozoite rate for $P$. falciparum. Rather, the lower prevalence of $P$. falciparum in high-coverage areas of the Wosera seems likely to be mediated by a UTN-caused reduction in circumsporozoite rates.

Theoretically, reductions in sporozoite rates might be achieved either by diverting mosquitoes on to alternative hosts, or by reducing vector survival. In Madang province, where $A n$. punctulatus was also the main malaria vector, BURKoT et al. (1990) found that introducing bednets resulted in a significant decrease in HBI, but insignificant declines in survival and vectorial capacity. However, few alternative hosts are available in Wosera and the HBI is uniformly high. It is therefore difficult to account for the area effects of the UTNs and, more specifically, the relationship between circumsporozoite rates in Wosera and UTN coverage except as a consequence of decreased survival of mosquitoes when they must penetrate a bednet in order to feed.

It is usually maintained that UTNs do not affect mosquito survival, but it seems likely that they do somewhat reduce vector viability. Faced with a bednet, a hostseeking mosquito can only complete the gonotrophic cycle if it finds its way both in and out of the net or finds altemative unprotected hosts. Mosquito fatigue or death at any point in this process reduces the sporozoite rate in proportion to the effect on vector survival (SAUL et al., 1990). In the longer term, effects of UTNs on transmission may be greater than the short-term effect on sporozoite rates, irrespective of whether this effect results from reduced gametocytaemia, diversion on to animal hosts, reduced mosquito survival, or all these combined, as appears likely in Wosera. This is because reduction in sporozoite rates causes decreased prevalence in humans and hence further reductions in mosquito infection via a positive feedback loop. A considerable period may be required for a new equilibrium to be reached, and quantitative models differ in their predictions about where this equilibrium will be located (DIETz, 1988). Only results from the field are likely to tell us what happens in any specific situation. 
In summary, the Wosera data indicate that, if coverage is high, long-term use of UTNs may have substantial impact on $P$. falciparum prevalence, more because of effects on vector bionomics than of individual protection. This interpretation follows from parallels between the patterns of circumsporozoite rates in $P$. vivax and $P$. falciparum, which both appear to be strongly affected by UTN coverage. It challenges the view that 'mass-killing effects', with reductions in survivorship, sporozoite rate and density of the mosquito vector population at a village level, occur specifically when ITNs are used consistently over a wide area against an anthropophilic vector (LiNes, 1996). We propose that such effects can occur even when coverage is patchy and the nets are not impregnated with insecticide. It is important to know whether UTNs have similar effects elsewhere, especially in areas of sub-Saharan Africa where An. funestus and the An. ganbiae complex are the main vectors.

\section{Acknowledgements}

We thank the Wosera villagers who generously agreed to participate in this study, the staff of Kunjingini Health Centre, and the Papua New Guinea Institute of Medical Research field staff in Madang and Maprik. We are grateful to Ivo Müller and Blaise Genton for useful discussions. Clearance for this research was given by the Medical Research Advisory Committee of Papua New Guinea. Field and laboratory work was supported by the United States Agency for International Development grant no. 9365967.89. Data analysis was supported by Swiss National Science Foundacion Grants No. 32-43427.95 and 3152984.97 .

\section{References}

Alpers, M. P., Al-Yaman F., Beck, H.-P., Bhatia, K., Hii, J., Lewis, D., Paru, R. \& \$mith, T. (1992). The malaria vaccine epidemiology and evaluation project of PNG: rationale and baseline studies. Papua New Guinea Medical Foumal, 35, $285-297$.

Beach, R. F., Ruebush, T. K. II, Sexton, J. D., Bright, P. L., Hightower, A. W., Breman, J. G., Mount, D. L. \& Oloo, A. J. (1993). Effectiveness of permethrin-impregnated bed nets and curtains for malaria control in a holoendemic area of western Kenya. American foumal of Tropical Medicine and Hygiene, 49, 290-300.

Bernardinelli, L. \& Montomoli, C. (1992). Empirical Bayes versus fully Bayesian analysis of geographical variation in disease risk. Statistics in Medicine, 11, 983-1007.

Binka, F. N., Indome, F. \& Smith, T. (1998). Impact of spatial distribution of permethrin-impregnated bed nets on child mortality in rural northem Ghana. American foumal of Tropical Medicine and Hygiene, 59, 80-85.

Burkot, T. R., Dye, C. \& Graves, P. M. (1989). An analysis of some factors determining the sporozoite rates, human blood indexes, and biting rates of members of the Anopheles puncrulatus complex in Papua New Guinea. American foumal of Tropical Medicine and Hygiene, 40, 229-234.

Burkot, T. R., Garner, P., Paru, R., Dagoro, R., Barnes, A., McDougall, S., Wirtz, R. A., Campbell, G. \& Spark, R. (1990). Effects of untreated bed nets on the transmission of Plasmodium falcipartm, $P$. vivax and Wuchereria bancrofti in Papua New Guinea. Transactions of the Royal Society of Tropical Medicine and Hygiene, 84, 773-779.

Campbell, H., Byass, P. \& Greenwood, B. M. (1987). Bed nets and malaria suppression. Lancet, $i, 859-860$.

Charlwood, J. D., Graves, P. M. \& Alpers, M. P. (1986). The ecology of the Anopheles punctulatus group of mosquitoes from Papua New Guinea: a review of recent work. Papua New Guinea Medical foumal, 29, 19-26.

Collins, F. H., Provell, P. M., Campbell, G. H. \& Collins, W. E. (1988). Monoclonal antibody-based enzyme-linked immunosorbent assay (ELISA) for detection of Plasmoditum malariae spotozoites in mosquitoes. American foumal of Tropical Medicine and Hygiene, 38, 283 288.

Dietz, K. (1988). Mathematical models for transmission and control of malaria. In: Malaria, Principles and Practice of Malariology, Wernsdorfer, W. H. \& McGregor, I. (editors). Edinburgh: Churchill Livingstone, pp. 1091-1134.

Genton, B., Hii, J., Al-Yaman, F., Paru, R,, Beck, H.-P., Ginny, M., Dagoro, H., Lewis, D. \& Alpers, M. P. (1994). The use of untreated bednets and malaria infection, morbidity and immunity. Annals of Tropical Medicine and Parasitology, 8, $263-270$

Genton, B., Al-Yarnan, F., Beck, H.-P., Hii, J., Mellor, S., Narara, A., Gibson, N., Smith, T. \& Alpers, M. P. (1995). The epidemiology of malaria in the Wosera area, East Sepik Province of Papua New Guinea, in preparacion for vaccine trials. I. Malariometric indices and immunity. Annals of Tropical Medicine and Parasitology, 89, 359-376.

Graves, P. M., Burkot, T. R, Carter, R., Cattani, J. A., Lagog, M., Parker, J., Brabin, B. J., Gibson, F, D., Bradley, D. J. \& Alpers, M. P. (1988). Measurement of malaria infectivity of human populations to mosquitoes in the Madang area, Papua New Guinea. Parasitology, 97, 25l-263.

Hii, J., Smith, T., Mai, A., Mellor, S., Lewis, D., Alexander, N, \& Alpers, M. P. (1997). Spatial and temporal variation in abundance of Anopheles species (Diptera: Culicidae) in a malaria endemic area in Papua New Guinea. Foumal of Medical Entomology, 34, 212-217.

Karch, S., Garin, B., Asidi, N., Manzambi, Z., Salaun, J. J. \& Mouchet, J. (1993). Moustiquaires impregnées contre le paludisme au Zaire. Annales de la Société Belge de Médecine Tropicale, 73, 37-53.

Lengeler, C. (1998). Insecticide treated bednets and curtains for malaria control (Cochrane Review). In: The Cochrane Library, Issue 3. Oxford: Update Software.

Lines, J. D. (1996). The technical issues. In: Net Gain, a New Method for Preventing Malaria Deaths, Lengeler, $\mathrm{C}$., Cattani, J. \& de Savigny, D. (editors). Geneva: IDRC/WHO, pp 17-53.

Lines, J. D., Curtis, C. F., Myamba, J. \& Niau, R. (1987). Tests of repellent or insecticide impregnated curtains, bednets and anklets against malaria vectors in Tanzania. Medical and Veterinary Entomology, 1, 37-51.

Magesa, S. M., Wilkes, T. I., Mnzava, A. E., Niunwa, K. J, Myamba, J, Kivuyo, M. D., Hill, N., Lines, J. D. \& Curtis, C. F. (1991). Trial of pyrethroid impregnated bednets in an area of Tanzania holoendemic for malaria. Part 2. Effects on the malaria vector population. Acta Tropica, 49, 97-108.

Muirhead-Thomson, R. C. (1954). Factors determining the true reservoir of Plasmodium falcipartom and Wuchereria bancrofit in a West African village. Transactions of the Royal Society of Tropical Medicine and Hygiene, 48, 208-225.

Robert, V. \& Carnevale, P. (1991). Influence of deltamethrin treatment of bed nets on malaria transmission in the Kou valley, Burkina Faso. Bulletin of the World Health Organization, 69, 735-740.

Saul, A. Graves, P. M. \& Kay, B. H. (1990). A cyclical feeding model for pathogen transmission and its application to determine vectorial capacity from vector infection rates. foumal of Applied Ecology, 26, 123-133.

Smith, T, Hii, J. L. K., Genton, B., Müller, I., Booth, M. Gibson, N., Narara, A. \& Alpers, M. P. (2001). Associations of peak shifts in age-prevalence for human malarias with bednet coverage. Transactions of the Royal Society of Tropical Medicine and Hygiene, 95, 1-6.

Snow, R, W., Rowan, K. M., Lindsay, S. W. \& Greenwood, B. M. (1988a). A trial of bed nets (mosquito nets) as a malaria control strategy in a rural area of The Gambia, West Africa. Transactions of the Royal Society of Tropical Medicine and Hygiene, 82, 212-215.

Snow, R. W., Lindsay, S. W., Hayes, R. J. \& Greenwood, B. M. (1988b). Permethrirn-treated bed nets (mosquito nets) prevent malaria in Gambian children. Transactions of the Royal Society of Tropical Medicine and Hygiene, 82, 838-842.

Snow, R. W., Shenton, F. C., I indsay, S. W., Greenwood, B. M., Bennett, S, Wheeler, J., Del Giudice, G., Verdini, A. S. \& Pessi, A. (1989). Sporozoite antibodies and malaria in children in a nural area of the Gambia. Annals of Tropical Medicine and Parasitology, 83, 559-568.

Snow, R. W., Peshu, N., Forster, D., Bomu, G., Mitsanze, E., Ngumbao, E., Chisengwa, R., Schellenberg, J. R., Hayes, R. J., Newbold, C. I. \& Marsh, K. (1998). Environmental and entomological risk factors for the development of clinical malaria among children on the Kenyan coast. Transactions of the Royal Society of Tropical Medicine and Hygiene, 92, 381-385.

Thomas, A., Spiegelhalter, D. J. \& Gilks, W. R. (1992). BUGS: a program to perform Bayesian inference using Gibbs sampling. In: Bayesian Statistics, volume 4, Bernardo, J. M., Berger, J. O., Dawid, A. P. \& Smith, A. F. M. (editors). Oxford: Clarendon Press, pp. 837-842.

Vounatsou, P., Smith, T. \& Gelfand, A. E. (2000). Spacial modelling of multinomial data with latent structure; an application to geographical mapping of human gene and haplotype frequencies. Biostatistics, 1, 177-189.

Wirtz, R. A, Zavala, F., Charoenvit, Y., Campbell, G. H., 
Burkot, T. R., Schneider, I., Esser, K. M., Be日udoin, R. L. \& Andre, R. G. (1987). Comparative testing of monoclonal antibodies against Plasmodium falciparum sporozoites for ELISA development. Bulletin of the World Health Organization, 65, 39-45.

Wirtz, R. A., Charoenvit, Y., Burkot, T. R., Esser, K. M., Beaudoin, R. L., Collins, W. E. \& Andre, R. G. (1991). Evaluation of monoclonal antibodies against Plasmodium vivax sporozoites for ELISA development. Medical and Veterinary Entonology, 5, 17-22.

Wirtz, R. A., Sattabongkot, J., Hall, T., Burkot, T. R. \& Rosenberg, R. (1992). Development and evaluation of an enzyme-linked immunosorbent assay for Plasmodium vivaxVK247 sporozoites. Foumal of Medical Entomology, 29, $854-857$.

Zimicki, S. (1996). Promotion in Sub-Saharan Africa. In: Net Gain, a New Method for Preventing Malaria Deaths, Lengeler, C., Cattani, J. \& de Savigny, $\mathcal{D}$. (editors). Geneva: IDKC, WHO,

pp. 111-147.

Received 8 September 1999; revised 16 fune 2000; accepted for publication 20 fune 2000

\title{
Announcements
}

\section{Joint International Tropical Medicine Meeting 2001 and Second International Tropical Medicine Update}

\author{
Chittagong, Bangladesh \\ 13-14 April 2001
}

This meeting will bring together the Bangladesh Association for Advancement of Tropical Medicine and the Royal Society of Tropical Medicine and Hygiene.

For further information contact the Meeting 2001 Secretariat, Didar Monzil, 1501 O R Nizam Road, Chittagong 4000 , Bangladesh; phone $+88031617986 / 671155 / 652088 / 654016$, fax $+88031650288 / 654016$, e-mail emran@spnetctg.com

\section{WorldLeish II \\ Crete, Greece \\ $20-24$ May 2001}

Second International Congress on Leishmania and Leishmaniosis

For further information contact the Congress Secretariat, Triaena Tours \& Congress S. A., Atchley House, 1 st Floor, 15, Mesogion Avenue, 11526 Athens, Greece; phone +3017499300 , fax +301 7705752, e-mail congress@triaenatours.gr

\section{XXth International Congress of Hydatidology}

$$
\begin{gathered}
\text { Kusadasi, Turkey } \\
\text { 4-8 Yune 2001 }
\end{gathered}
$$

For further details contact the Secretariat, XXth Congress of Hydatidology, Ege University Medical Faculty, Department of Parasitology, 35100 Bornova-Izmir, Turkey; phone/fax +90 232373 1073, e-mail hydatid@med.ege.edu.tr, website www.med.ege.edu.tr/ hydatid 